\title{
FRAGMENTO E TODO: DUAS IMAGENS URBANAS ENTRE ORIENTE E OCIDENTE, C. 1600
}

\author{
FRAGMENT AND WHOLE: TWO URBAN IMAGES BETWEEN EAST AND WEST, CA. $1600 \mid$ \\ FRAGMENTO Y TODO: DOS IMÁGENES URBANAS ENTRE ORIENTE Y OCCIDENTE, C. 1600
}

PEDRO PAULO PALAZZO

\begin{abstract}
RESUMO
Este artigo analisa as formas de representação de cidades em duas ilustrações produzidas por volta de 1600: a gravura de Macau, por Theodor de Bry, e a vista de Quioto, atribuída a Iwasa Katsumochi Matabei. Investiga-se a relação entre formas de representação fragmentária e global em ambas as imagens. A gravura europeia da cidade retrata o espaço urbano como um todo, enquanto a pintura japonesa representa uma série de fragmentos separados por nuvens douradas. Entretanto, a imagem global da figura europeia é fragmentada pela multiplicidade de perspectivas concomitantes, ao passo que o biombo japonês tem uma ordem global subjacente gerada pela projeção cavaleira. Em ambos os casos, há interação entre olhares fragmentados e uma visão de conjunto que se relacionam de modos variados.
\end{abstract}

PALAVRAS-CHAVE: Cidade oriental. Fragmento. Funaki. Iconografia. Iwasa Katsumochi Matabei. Theodor de Bry.

\section{ABSTRACT}

This article analyzes representations of cities in two pictures created around 1600: Theodor de Bry's engraving of Macao, and the views of Kyoto attributed to Iwasa Katsumochi Matabei. The relationship between fragmented and total forms of representation is studied in both pictures. The European engraving depicts urban space as a whole, while the Japanese painting portrays a number of fragmentary scenes separated by golden clouds. However, the global picture in the European print is fragmented by the multiplication of simultaneous perspectives, while the Japanese screen displays underlying global order due to its cavalier projection. In both cases there is interaction between fragmentary views and a global outlook that relate in diverse ways.

KEYWORDS: East Asian city. Fragment. Funaki. Iconography. Iwasa Katsumochi Matabei. Theodor de Bry. 


\section{RESUMEN}

Este artículo analiza las formas de representación de ciudades en dos ilustraciones producidas alrededor de 1600: el grabado de Macau, por Theodor de Bry, y la vista de Quioto, atribuida a Iwasa Katsumochi Matabei. Se investiga la relación entre formas de representación fragmentaria y global en ambas imágenes. El grabado europeo de la ciudad retrata el espacio urbano como un todo, mientras la pintura japonesa representa una serie de fragmentos separados por nubes doradas. Sin embargo, la imagen global de la figura europea es fragmentada por la multiplicidad de perspectivas concomitantes, al paso que el biombo japonés tiene un orden global subyacente generado por la proyección caballera. En ambos casos, hay interacción entre miradas fragmentadas y una visión de conjunto que se relacionan de modos variados.

PALABRAS-CLAVE: Ciudad oriental. Fragmento. Funaki. Iconografía. Iwasa Katsumochi Matabei. Theodor de Bry.

\section{INTRODUÇÃO}

Este artigo analisa as formas de representação de cidades em duas ilustrações criadas entre o final do século XVI e o início do XVII: a gravura de Macau, por Theodor de Bry (1528-1598) (Figura 1), publicada postumamente no Indiae Orientalis, em 1607, e o par de biombos Funaki, com vista de Quioto, atribuído a Iwasa Katsumochi Matabei (1578-1650), pintado entre 1614 e 1615 (Figura 2) (Kita, 1999). Em particular, investiga-se a relação entre formas de representação fragmentária e global em ambas as imagens.

O século XVI foi um período de efervescentes trocas econômicas e culturais entre a Europa e o Extremo-Oriente. O intercâmbio entre Oriente e Ocidente datava da Antiguidade - a China teria sido diretamente conhecida dos romanos desde o século II d.C. e diversas missões comerciais e políticas partiram da Europa e do mundo árabe em direção aos mongóis na China no século XIII. A despeito da ênfase comercial na rota da Índia, a partir da viagem de Vasco da Gama, as regiões mais orientais da Ásia entraram gradualmente no mapa político europeu, principalmente a partir das missões de São Francisco Xavier e Alessandro Valignano, no Japão, e de Matteo Ricci e Adam Schall, na China, na segunda metade do século XVI e início do XVII (Lach, 1965).

Os contatos mútuos entre essas culturas orientais e ocidentais vieram acompanhados, no final do século XVI, de representações mútuas: de um lado, os europeus avidamente mapeavam e retratavam os países que exploravam; de outro, os japoneses principalmente, não menos curiosos, representavam a chegada dos estrangeiros nos namban-e ("imagens dos bárbaros do sul") (Mason, 1993). No contexto dessas representações cruzadas, contudo, fica claro que o espaço privilegiado do encontro é a cidade oriental. Nesse âmbito, o inconsistente e o fragmentário ainda sinalizavam a abertura para o maravilhoso 

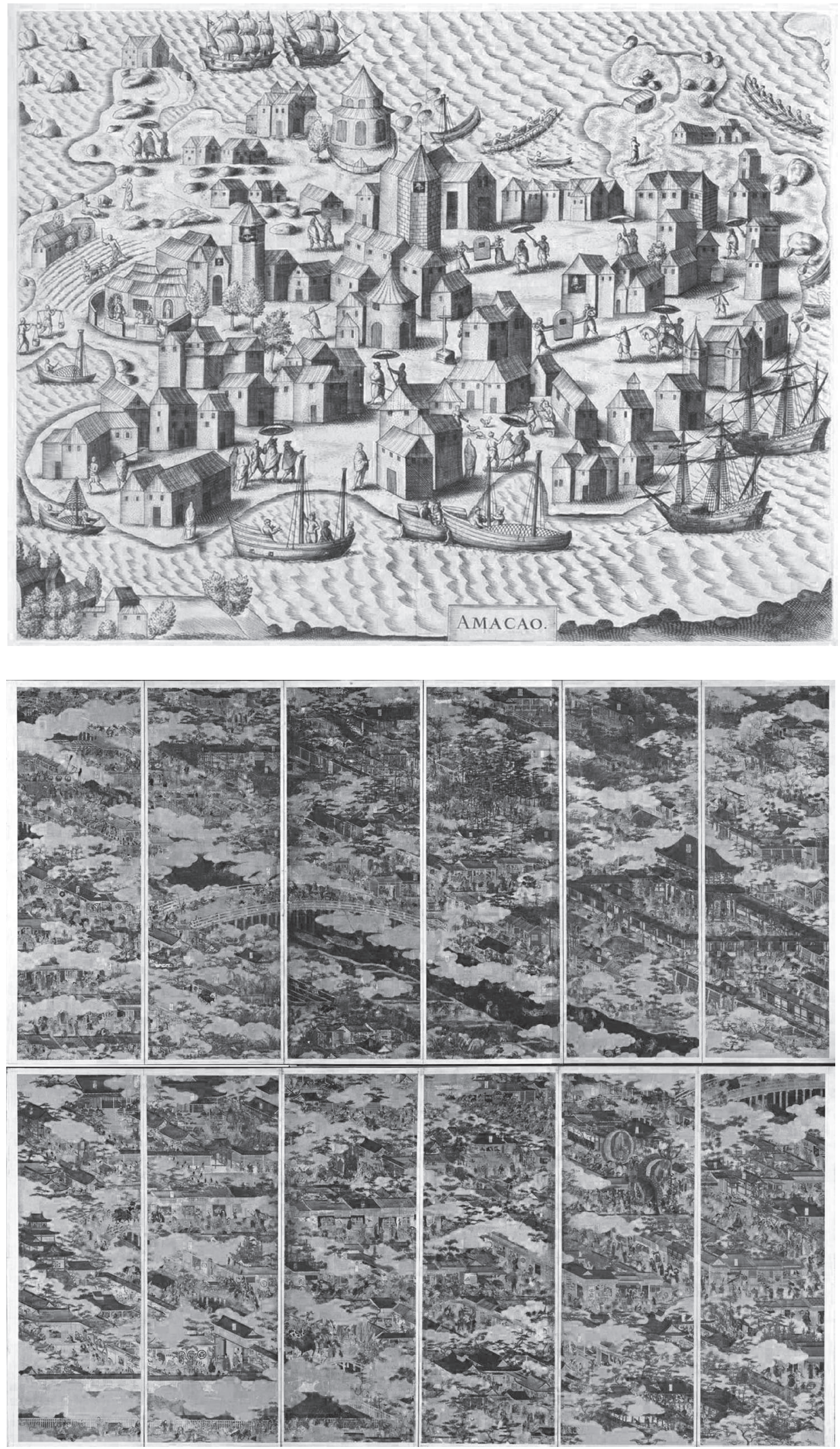

FIGURA 1 - Vista de

Macau, por Theodor de Bry — lâmina XII.

Fonte: Bry e Bry (1607).
FIGURA 2 - Par de biombos "Funaki", atribuído a Iwasa Katsumochi Matabei, 1614-1615.

Fonte: Museu Nacional de Tóquio, $\mathrm{n}^{0}$ de acervo A-11168, fotomontagem dos slides $n^{\circ}$ C0004929 a C0004934. Disponível em: $<$ http://webarchives.tnm. jp/imgsearch/show/ C00049 29>. Acesso em: 8 nov. 2012. 
e para o inesperado, espaço que começou a se retrair, tanto do lado europeu, devido ao cientificismo crescente (Palazzo, 2010), quanto do oriental, devido ao engessamento administrativo e social (Totman, 1993), somente a partir de meados do século XVII.

\section{CONCEPÇÕES ESPACIAIS}

\section{QUIOTO}

O par de biombos Funaki, pintado por Matabei, se reporta à tradição das pinturas rakuchū rakugai zu (洛中洛外国), termo que pode ser traduzido como desenhos (ou vistas) dentro e fora da capital. Trata-se de vistas de Quioto e de seu entorno, gênero especialmente popular entre o início do século XVI e a primeira metade do século XVII. Frequentemente retratava o festival Gion, uma das principais celebrações religiosas na capital (Guth, 1996; Kita, 1999).

A imagem de Quioto imortalizada nesse par de pinturas é, literalmente, a de um espaço fragmentado. Como é comum ao conjunto das obras desse gênero, o desenho não abarca a extensão inteira da área urbanizada, sendo abruptamente cortado nas extremidades dos biombos. A continuidade das ruas retilíneas é interrompida com frequência por grandes massas de nuvens douradas, e, singularmente nessa obra de Matabei, não há uma hierarquia de edificações ou espaços urbanos que permita uma leitura global da estrutura urbana.

A discussão acerca da falta de legibilidade global da cidade do Extremo-Oriente, especialmente da japonesa, não é nova. A recíproca legibilidade da cidade europeia tem sido ocasionalmente atribuída à sua ênfase nos alinhamentos monumentais (Neiva, 2003) — tese questionada por Holanda (2002), que aponta a ocorrência de inteligibilidade espacial em tecidos urbanos não monumentalizados. Alternativamente, já se invocou a invenção da projeção perspectiva linear, no Renascimento, como análogo ao desenvolvimento de "perspectivas" e métricas globais sobre o território (Santos, 2002). Uma perspectiva divergente sugere que as capitais japonesas, antes que ilegíveis por princípio, tenham sido concebidas com uma clareza monumental que tendeu a se diluir com o tempo: "Para o Japão, os padrões de urbanidade principesca foram estabelecidos na China, que havia fornecido o modelo das primeiras cidades japonesas, as capitais em Heijō-kyō (Nara), fundada em 710, e sua sucessora a partir de 794, Heian-kyō (hoje Quioto)" (Smith, 1979, p.61, tradução minha) ${ }^{1}$.

No entanto, a imagem axial e visualmente ordenada do modelo chinês não se mostrou duradoura no Japão:

O cinturão murado crucial [da capital chinesa] nunca foi construído nem em Nara, nem em Quioto, e a simetria da planta se decompôs cedo enquanto a cidade crescia para leste em direção às montanhas, um ambiente mais compatível com o temperamento urbano japonês. Quioto, a capital imperial durante mais de mil anos, $[\ldots]$ aos poucos foi ganhando um aspecto relativamente pouco principesco (Smith, 1979, p.63, tradução minha) ${ }^{2}$. 
Assim, em que pese a persistência, ainda no século XVIII, de uma relativa ortogonalidade na malha urbana de Quioto, fica claro numa estampa alemã da época (Figura 3) que essa regularidade formal não é acompanhada dos acentos espaciais centralizadores, característicos da cidade ocidental — como ocorrência de praças ou clareza na hierarquia viária. A imagem resultante é a de uma cidade geometricamente regular, porém perceptivamente labiríntica.

A fragmentação da cidade é a característica mais evidente no par de biombos. Trechos de ruas são mostrados entrecortados por espessas massas de nuvens douradas que ocultam não só boa parte dos interiores de quarteirão, mas também as relações e conexões entre as ruas aparentes. $\mathrm{O}$ artista criou, assim, um arquipélago de ambientes urbanos visualmente isolados uns dos outros. O efeito estético das superfícies douradas é evidente ao se observar o conjunto da obra, ainda mais imaginando a iluminação cintilante de velas ou lamparinas sob a qual ela teria sido vista originalmente (Mason, 1993).

Historicamente, o emprego de nuvens douradas em composições pictóricas pode ser associado a exemplares de pintura chinesa da dinastia Ming (Figura 4). Todavia, o uso das nuvens douradas nas pinturas de tipo rakuchū rakugai zu não era apenas, como na

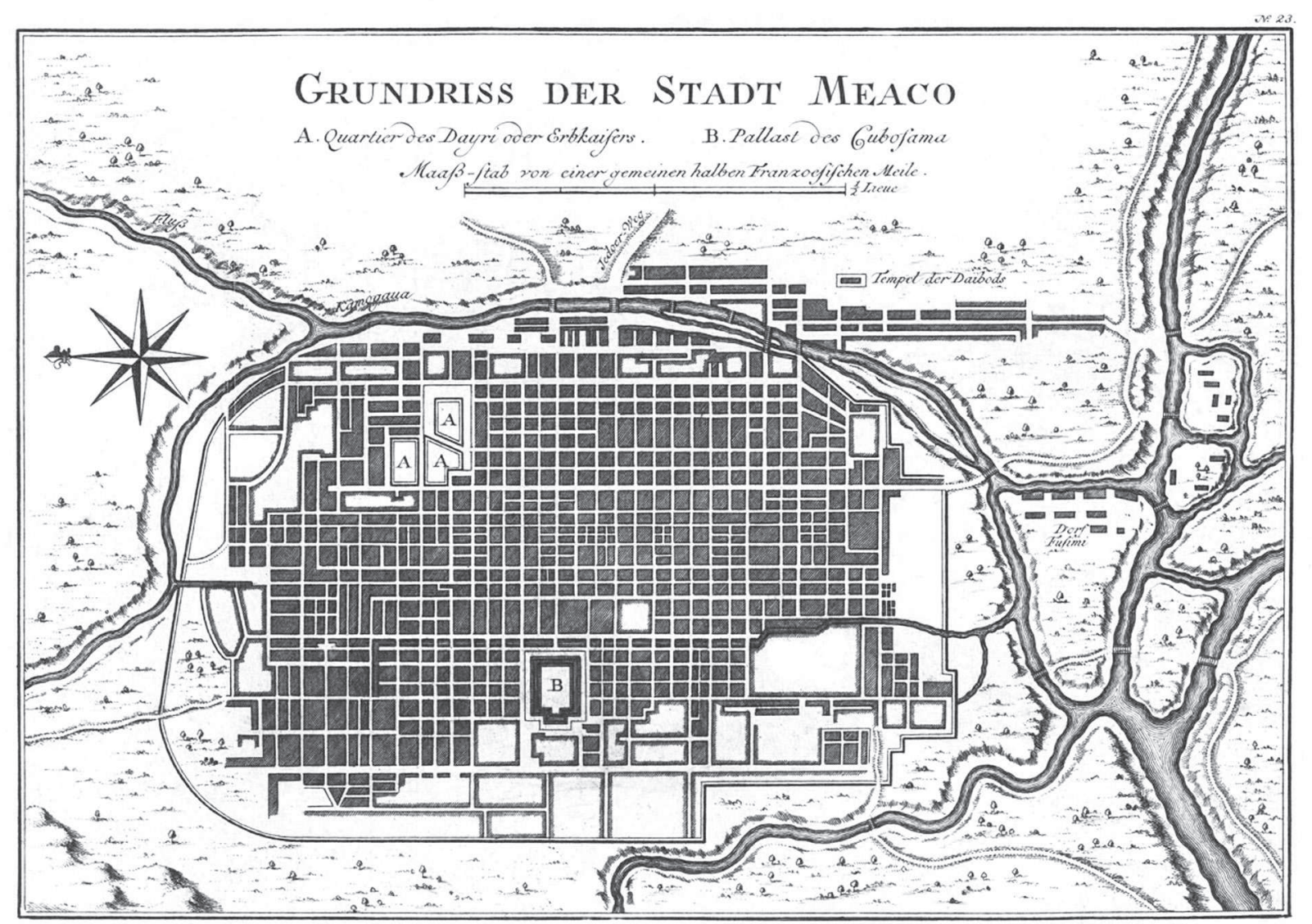

FIGURA 3 - Planta da cidade de Quioto.

Fonte: Bellin (1758). 


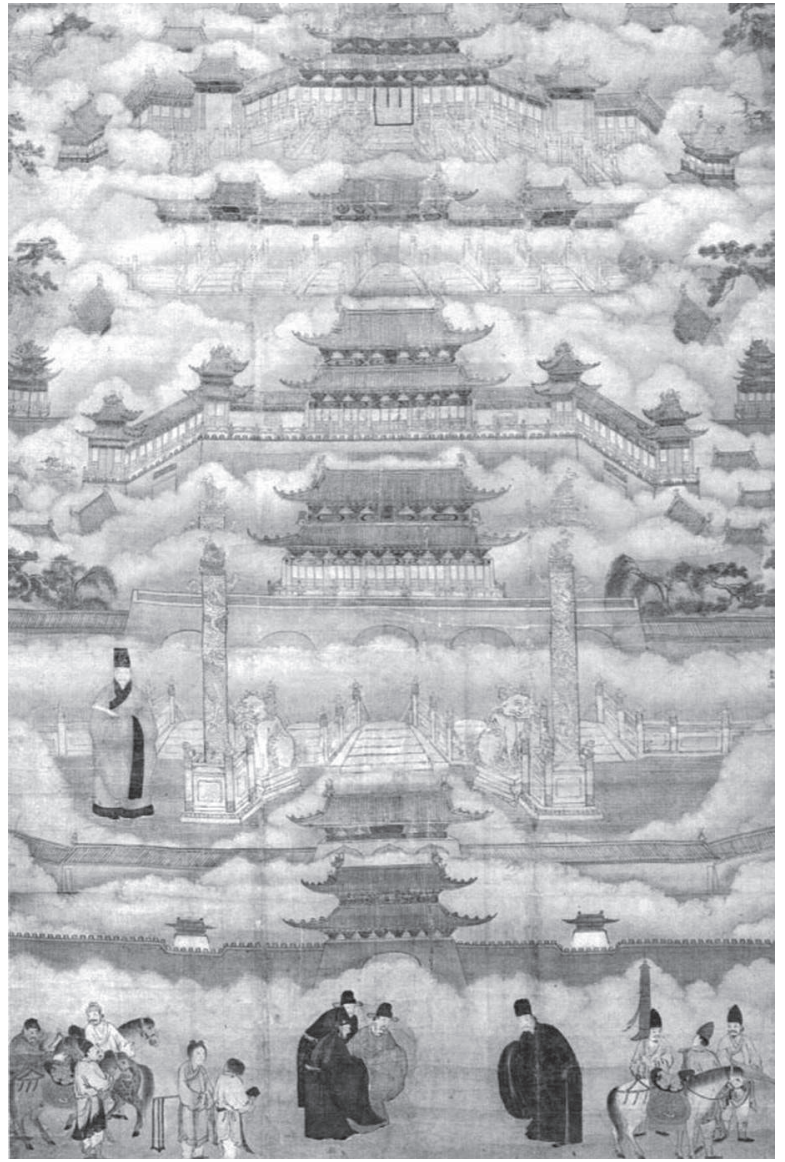

FIGURA 4 - Retrato de funcionário diante da cidade proibida (Pequim). Nanquim e aquarela sobre seda. Dinastia Ming, século XV.

Fonte: OTrustees of the British Museum. $\mathrm{N}^{0}$ de acervo $1881,1210,0.87$. CHAN259733, imagem n ${ }^{0}$ AN259733001. Disponível em: <http://www. britishmuseum.org/system_pages/ beta_collection_introduction/beta collection_object_details.aspx?obje ctld $=270684 \&$ partld $=1 \&$ searchText =portrait $\% 20$ of $\% 20$ an $\% 20$

official\%20in\%20front\%20 of\%20 the\%20forbidden $\% 20$ city>. Acesso em: 30 dez. 2012.

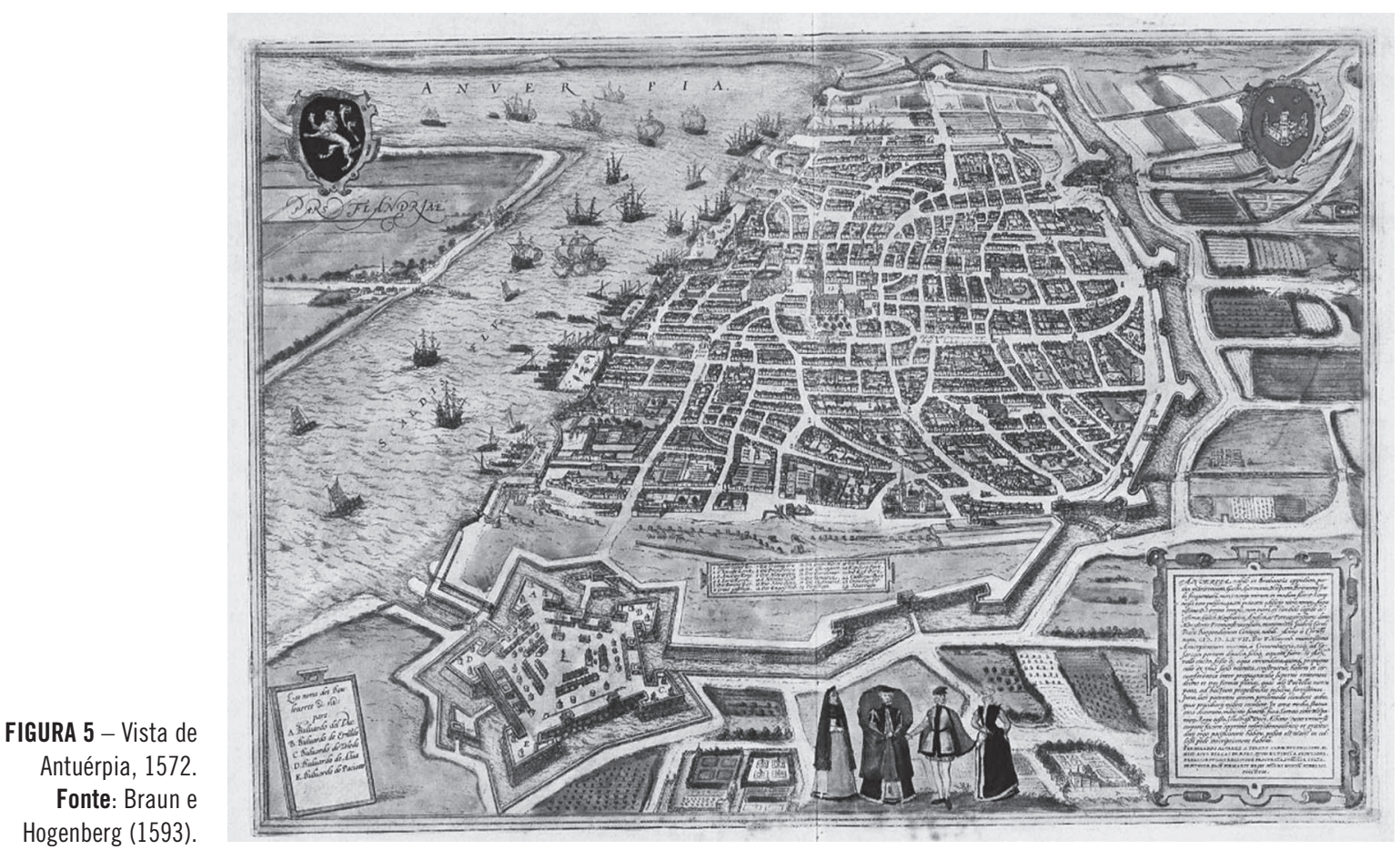

Oculum ens. | Campinas | 10(1) | 73-85 | Janeiro-Junho 2013 
pintura chinesa, um expediente decorativo. Em primeiro lugar, é importante notar que todo o plano original de Quioto, do século VIII, não chegou a ser inteiramente ocupado antes do século XIX; além disso, várias partes anteriormente edificadas da cidade foram incendiadas no século XIV e demoraram a serem reconstruídas (Fujita \& Koga, 1999). Nesse caso, as nuvens serviriam para ocultar trechos desolados da cidade.

Além dessa função prática das nuvens douradas como expediente de composição pictórica, há outra mais pregnante com respeito à representação política da cidade na segunda metade do século XVI: a indicação das comunidades semiautônomas dos machi como sujeitos coletivos da identidade urbana, como será visto mais adiante.

\section{MACAU}

A estampa de Theodor de Bry é uma vista geral da cidade de Macau, exagerando bastante o tamanho da área urbanizada com respeito à dimensão total da península. Assim como nos biombos, não há aqui a intenção de mapear, mas, sim, de ilustrar o conjunto urbano. O modo de representação é bastante simplificado, em contraste com outras projeções exaustivas de cidades europeias ou chinesas, realizadas por autores ocidentais na mesma época (Figura 5). A gravura assemelha-se bastante às perspectivas de tabas brasileiras e aldeias norte-americanas, retratadas pelo próprio Theodor de Bry bem como por outros artistas desde meados do século XVI.

Contrariamente à pintura do rakuchū rakugai zu, o universo pictórico não é subdividido em cenas isoladas nem truncado de modo aparentemente arbitrário; o artista busca mostrar o espaço urbano na sua totalidade, enquadrado não por uma moldura artificial, mas por suas divisas por assim dizer naturais: espaço rural e mar. E, de modo semelhante à pintura japonesa, há a combinação de elementos arquitetônicos com a presença de figuras humanas aparentemente retratadas em seus afazeres diários.

Essa representação convencional de uma cidade por inteiro, vista em perspectiva, associada a uma representação de seus habitantes em trajes típicos não é nada incomum no século XVI, uma vez que na própria Europa a diversidade de formas urbanas e de costumes locais nessa época ainda era grande (Figura 5). A visão de conjunto é preponderante por retratar a própria definição de cidade como uma totalidade delimitada, dotada de seus costumes e, significativamente, de suas particularidades políticas (Pavia, 1982).

Transposta para os novos mundos, orientais ou ocidentais, a perspectiva aérea — imaginária, portanto —, de assentamentos humanos preservava essa busca pela totalidade, versão pontual e reduzida do ideal tipicamente quinhentista da Cosmografia. O paralelo com a obra cosmográfica, escrita e, portanto, mais interpretativa do que projetiva, é ainda mais significativo dada a clara separação que se estabelece entre vista e mapa; o mapa renascentista com sua determinação geométrica, já que era instrumento de navegação (Santos, 2002), não pertencia mais ao mesmo referencial da vista, interpretativa por natureza e, portanto, apta a prescindir do rigor projetivo em nome da força comunicativa. 
De fato, a gravura de Theodor de Bry, com seu ideal de totalidade aparente à primeira vista, não tem nada de sistemática: cada edifício, praticamente, segue uma projeção diferente do próximo, geralmente sem aderir nem a uma vista estritamente paralela, nem a uma perspectiva linear construída segundo os padrões já então bem conhecidos na arte europeia; mesmo o dimensionamento dos elementos faz pouco para reforçar o efeito de perspectiva. Essa fragmentação projetiva, em contraste aparente com a unidade conceitual do enquadramento, tem o efeito de neutralizar a hierarquia urbana, relativizando o destaque de marcos arquitetônicos tais como o templo circular na parte superior ou a torre na parte central da cidade. A mesma neutralidade política, por assim dizer, é visível em desenhos europeus da mesma época. Porém, nestes, ao contrário, era o rigor projetivo que neutralizava a dominância de palácios e igrejas.

\section{REPRESENTAÇ̃̃O POLÍTICA}

A estampa de Theodor de Bry pertence, portanto, àquela categoria de vistas urbanas na qual o verniz etnográfico mascarava uma imagem drenada de representatividade política: "[...] a atenção se concentra na cidade de pedra, [... a a "massa física" dificilmente se dirige para o interior das casas, não penetra na organização do trabalho, não se detém nas condições da vida material" (Pavia, 1982, p.111, tradução minha) ${ }^{3}$.

A olhar de perto, percebe-se que, na gravura de Theodor de Bry, o único personagem a interagir com seu meio físico é o agricultor, no extremo esquerdo da imagem. Todas as outras figuras humanas estão, decerto, envolvidas em atividades - na maioria delas, o circular pela cidade. No entanto, não travam qualquer tipo de contato com a arquitetura, ao contrário dos personagens dos biombos, que interagem intensamente no espaço e com o espaço. O citadino de Theodor de Bry parece indiferente ao seu espaço urbano, tal como nas vistas urbanas produzidas pelos seus contemporâneos europeus.

A intensa interação na pintura dos biombos, por outro lado, não é apenas trivial, retratando cenas do cotidiano destituídas de significado, mas tem também uma relevância política, demonstrando a ligação dos agentes urbanos entre si e com o seu espaço (Kita, 1999). Em geral, a historiografia da cidade sustenta, ao contrário, que há antítese entre a concepção ocidental de cidadania e a organização política das cidades orientais, o que se reflete na já mencionada "ilegibilidade" destas, evidenciada pela falta de hierarquia em seus espaços de convivência pública. Segundo Zucker (1970, p.19, tradução minha) ${ }^{4}$ :

\footnotetext{
Isso pode ser explicado sociologicamente: apenas no seio de uma civilização na qual o ser humano anônimo se tornara um "cidadão”, onde a democracia havia desabrochado até certo ponto, poderia o lugar de encontro se tornar suficientemente importante a ponto de tomar uma forma específica.
}

Oculum ens. | Campinas | 10(1) | 73-85 | Janeiro-Junho 2013 
Circunscreve-se, implicitamente, o universo da politização do espaço público ao das civilizações de matriz greco-romana, berço do conceito de "cidadania". Consequentemente, argumenta-se que:

O conceito de uma ordem "cívica" é tão intrínseco à idéia ocidental moderna da cidade que vários autores partiram do princípio de que fosse um elemento indispensável na tradição urbana de qualquer cultura. É um conceito, porém, que ou está ausente ou tem pouca relevância em praticamente todas as culturas não ocidentais (Smith, 1979, p.76 , tradução minha, grifo do autor) ${ }^{\mathbf{5}}$.

Essa ausência do conceito de representatividade política não significa, porém, que não existisse uma identificação dos residentes da cidade com assuntos públicos. O espaço urbano era dividido em quadrantes conhecidos como chō ou machi — este último termo pode ser escrito com o mesmo ideograma de chō (町), ou com outro que também significa "rua” (街). Cada quadrante seria formalmente governado por um administrador responsável perante o xogunato, o machi-bugyō. No entanto, "Esse burocrata não governava diretamente os machi-chi [habitantes do machi], pois cada chō era autogerido baseado em princípios de responsabilidade coletiva semelhantes aos do mura [vila] rural" (Smith, 1979, p.79, tradução minha) ${ }^{6}$.

A olhar mais de perto, a organização da pintura, com seus setores urbanos claramente divididos entre si, parece retratar um conjunto de chō e suas respectivas divisas territoriais. O machi em questão, nesse caso, é muito mais aquele da rua coletiva (街) do que o do quadrante burocrático (町). Kita (1999) sustenta que essa fragmentação por ruas, caracterizando muito mais claramente espaços urbanos autônomos do que elementos de uma ordem administrativa centralizada, é, de fato, um retrato da ordem política de Quioto entre os séculos XIV e XVI. Nessa época, a insegurança causada pela guerra civil forçou os citadinos a se organizarem por área territorial, em relativo detrimento das divisões por classe social ou cargo político:

Todos os habitantes de uma certa área faziam frente a um perigo comum. Por força das circunstâncias, eles tinham que responder conjuntamente. A sua reação conjunta a um ataque externo é vista por Hayashiya como a força por trás do desenvolvimento da cooperação entre ricos e pobres, a qual por sua vez transformou o machi de entidade geográfica em entidade social (Kita, 1999, p.145, tradução minha) ${ }^{7}$.

Existe, portanto, uma clara leitura identitária na produção do par de biombos, a qual transcendia o problema da falta de representatividade política das classes urbanas:

A pouca força da identidade política entre as massas populares [...] não deve ocultar um senso real e crescente de identidade cultural, uma qualidade que se articula com 
o crescimento do mercado editorial popular, e que tende a ser negligenciada por quem se concentra na estrutura institucional da cidade(Smith, 1979, p.80, tradução minha) ${ }^{8}$.

Disso resulta que, na verdade, a fragmentação do espaço é modo de expressar certa construção da identidade citadina; de fato, a cidade é dividida em trechos, mas não se percebe heterogeneidade significativa entre esses trechos. Todos retratam casas, estabelecimentos comerciais, clérigos, plebeus e membros da elite - nobres ou burgueses refinados (Figura 6). Os edifícios representativos do poder religioso não têm uma dominância clara com respeito à malha urbana (Kita, 1999). A homogeneidade espacial fornecida pela projeção cavaleira reforça esse equilíbrio na diversidade, formando um "arquipélago" de entidades espaciais semelhantes, porém não ainda aplastadas por um poder centralizador (Lefaivre \& Tzonis, 2012). Nesse sentido, a própria ausência de edificações representativas do regime político é politicamente significativa. O conjunto retrata claramente a cidade do ponto de vista de um participante da vida urbana mais do que pela vista distanciada do poder político ou de um viajante neutro (Mason, 1993).

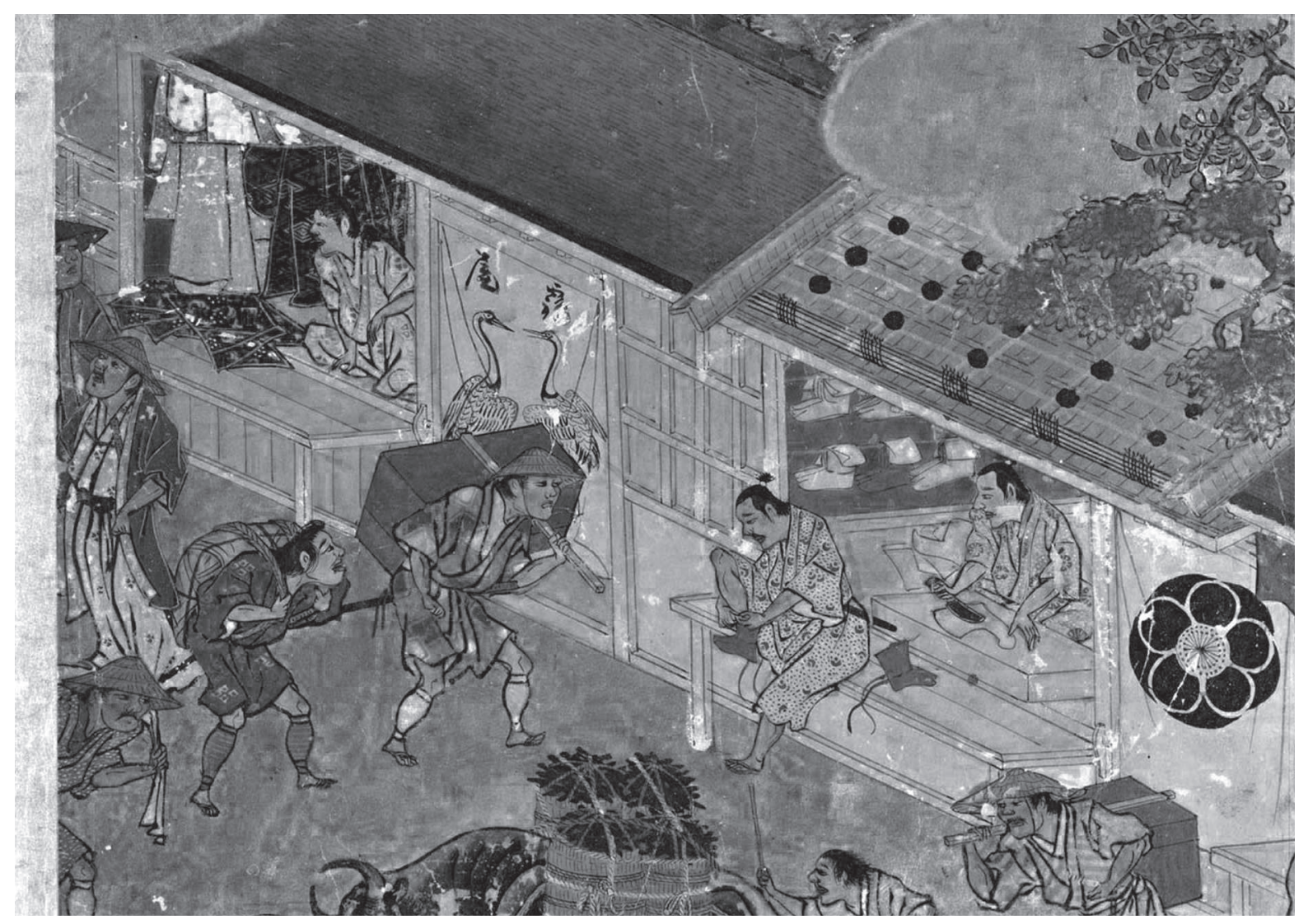

FIGURA 6 - Biombos "Funaki", detalhe.

Fonte: Museu Nacional de Tóquio. № de acervo A-11168, slide n C0006740. Disponível em: <http://webarchives.tnm.jp/imgsearch/show/ C0006740>. Acesso em: 8 nov. 2012. 


\section{CONCLUSÃO}

Ambas as ilustrações, a estampa de Macau, por Theodor de Bry, e o par Funaki de biombos, atribuído a Matabei, apresentam uma fértil interação entre aspectos globais e fragmentados. No caso da gravura europeia, a vista completa da cidade contrasta com seus elementos inconsistentes ou justapostos sem integração. Na pintura japonesa, a vista fragmentada em setores separados por nuvens em folha de ouro deixa transparecer uma ordem projetiva geral contendo elementos e personagens intensamente articulados entre si.

A constatação desse jogo entre o fragmento e o todo tem mais do que relevância estética, pois revela atitudes políticas diante da cidade. A representação unitária da cidade é a europeia, posto que no ocidente desde o final da Idade Média as cidades emergiam como centros não apenas econômicos, mas também políticos, dotados de sua própria administração ainda que dominados pelos Estados cada vez mais centralizados do Renascimento. No interior dessa visão global da cidade, no entanto, há uma justaposição de elementos isolados; o artista nesse momento ainda não sistematizava o universo de cima para baixo, mas inicialmente dava conta da diversidade nele existente.

Na representação fragmentada da cidade japonesa, o leitor ocidental pode ver a propalada ilegibilidade do conjunto urbano. Entretanto, tal fragmentação também retratava a inexistência de uma administração unitária. A homogeneidade dos fragmentos entre si, por outro lado, enfatizava o senso de pertencimento do artista e de seu cliente às células citadinas, numa época em que a autonomia dessas já se encontrava em declínio. Desenrolava-se no par de biombos o último ato de um ideal de cultura combinando o refinamento da aristocracia civil e o dinamismo da burguesia mercantil, cultura que em pouco tempo seria segregada à força pela centralização administrativa do xogunato Tokugawa.

Em ambos os casos, delineia-se a questão da particularidade mascarada pela padronização. Há pouco de tipicamente oriental na estampa de Macau; a arquitetura anônima e os figurinos apenas ligeiramente orientalizantes podem remeter a uma filtragem das diferenças diante do olhar explorador. Podem, também, com a ambiguidade característica das imagens, sinalizar uma abertura para considerar o outro como não irreconciliável com o europeu. A quase que literal cortina de fumaça dourada no biombo de Quioto permite a expressão velada do seu elemento de divergência política. O etéreo e o informe espacializam a matéria e a forma da vida social.

Vários outros fios condutores restam para serem explorados na interação entre essas vistas urbanas. Cabe indagar-se sobre as relações entre as duas imagens e outras representações contemporâneas. A vista de cidade é, por um lado, um subconjunto de informações extraídas do inesgotável acervo da vida urbana; por outro lado, ao ficcionalizar a cidade, abre outras tantas inesgotáveis possibilidades de leitura de ideais urbanos que vão além do que o suporte material da cidade pode oferecer em cada dado momento. 


\section{NOTAS}

1. "For Japan, the standards of princely urbanity were set by China, which had provided the model for the first Japanese cities, the capitals of Heijo-kyō (Nara), founded in 710, and its successor from 794, Heian-kyō (now Kyoto)".

2. "The crucial enclosing walls remained unbuilt in both Nara and Kyoto, and the symmetry of the plan soon crumbled as the city grew eastward into the hills, a more compatible environment for the Japanese urban temperament. Kyoto, the imperial captial for over one thousand years [...], gradually assumed a relatively unprincely aspect".

3. "[...] l'attenzione si concentra nella città di pietra, [...] la "masa fisica", difficilmente si indirizza verso l'interno delle case, non penetra nell'organizzazione del lavoro, non si sofferma sulle condizioni della vita materiale".

4. "This may be explained sociologically: only within a civilization where the anonymous human being had become a "citizen," where democracy had unfolded to some extent, could the gathering place become important enough to take on a specific shape".

5. "The concept of a "civic" order is so much a part of the modern Western idea of the city that many writers have assumed it to be an indispensable element in the urban tradition of any culture. However, it is a concept that is either absent or of small consequence in virtually every non-Western culture".

6. "This official did not directly govern the machi-chi, for each cho was self-governed on principles of collective responsibility similar to those of the rural mura".

7. "All inhabitants of a given area thus faced a common danger. By force of circumstance, they had to respond communally. Their shared reaction to outside attack Hayashiya sees as the force behind the development of cooperation between rich and poor, which, in turn, transformed the machi from a geographic entity into a social one".

8. "The weakness of political identity among the commoner masses [...] should not obscure a real and indeed growing sense of cultural identity, a quality which became articulate with the emergence of popular publishing and which tends to be neglected by those who focus on the institutional structure of the city".

\section{REFERÊNCIAS}

BELLIN, N. Grundriß der stadt meaco. Leipzig: Merkur, 1758.

BRAUN, G.; HOGENBERG, F. Civitates orbis terrarum. Cologne: [s.n.], 1593.

BRY, J.T.; BRY, J.I. Indiae orientalis pars octava. Frankfurt: Johann Theodor de Bry, 1607.

FUJITA, M.; KOGA, S. Nihon kenchiku shi. Tōkyō: Shōwadō, 1999.

GUTH, C. Japanese art of the edo period. London: Calmann and King, 1996.

HOLANDA, F. O espaço de exceção. Brasília: UnB, 2002.

KITA, S. The last Tosa: Iwasa Katsumochi Matabei, Bridge to Ukiyo-e. Honolulu: University of Hawai'i Press, 1999.

LACH, D.F. Asia in the making of Europe. Chicago: University of Chicago Press, 1965.

LEFAIVRE, L.; TZONIS, A. Architecture of regionalism in the age of globalization: peaks and valleys in the flat world. Abingdon: Routledge, 2012.

MASON, P.E. History of japanese art. New York: Abrams, 1993.

NEIVA, S.L.G. Calçados sobre tatami: a ilegilidade das cidades japonesas. Vitruvius, 041.01, ano 4, 2003. Disponível em: <http://www.vitruvius.com.br>. Acesso em: 23 mar. 2006.

PALAZZO, C.L. Entre mitos, utopias e razão: os olhares franceses sobre o Brasil (séculos XVI a XVIII). 2.ed. Porto Alegre: EdiPUCRS, 2010. 
PAVIA, R. L'idea di città XV-XVIII secolo. Milano: Franco Angeli, 1982.

SANTOS, D. A reinvenção do espaço: diálogos em torno da construção do significado de uma categoria. São Paulo: Unesp, 2002.

SMITH, H.D. Tokyo and London: comparative conceptions of the city. In: CRAIG,A.M. (Org.) Japan: a comparative view. Princeton: Princeton University Press, 1979. p.49-99.

TOTMAN, C.D. Early modern Japan. Berkeley: University of California Press, 1993.

ZUCKER, P. Town and square: from the agora to the Village Green. Cambridge: MIT Press, 1970.

PEDRO PAULO PALAZZO Professor Doutor | Universidade de Brasília | Faculdade de Arquitetura Recebido em 7/11/2012 e aceito e Urbanismo | Campus Darcy Ribeiro, ICC Ala Norte Bloco A, 70910-900, Brasília, DF, Brasil | para publicação em E-mail:<palazzo@unb.br>. 